\title{
Paul Higgs and Chris Gilleard (2016). Personhood, Identity and Care in Advanced Old Age. Bristol: Policy Press. ISBN 978-1-4473-1906-1 (Paperback)
}

\author{
REVIeWed by Michael Fine*
}

Paul Higgs and Chris Gilleard, two British cultural sociologists familiar to the readers of this journal, have a prolific publishing record. They are perhaps best known for a series of books and articles on the topic of "cultures of ageing," a phrase they used as the title of what is surely one of the most important and influential books published in the field of cultural gerontology (Gilleard \& Higgs 2000).

This book, Personhood, Identity and Care in Advanced Old Age, builds on and consolidates a number of central concerns in their most recent writings on what they refer to as "the fourth age" (Gilleard \& Higgs 2010; Higgs \& Gilleard 2014, 2015) which follows and contrasts with the "active ageing" of the third age. The book addresses the fourth age as a life stage involving "ageing without agency," a final and abject period of life that both reflects and underlies the experience of frailty and dependency in the final advanced years of a long life. They frame this final stage of life as a "social imaginary," a culturally shared understanding of the humiliation, dependency, impotence, infirmity and abjection that they argue "seems to surround the social position of those at the extremes 
International Journal of Ageing and Later Life

of later life." They then draw on this analysis to examine the limits to care; the possibilities that circumscribe both informal and formal care relationships; and the links between ageing, modernity and identity. The result is a theoretically rich, exciting, controversial, important, if at times ponderous, and densely written treatise on the possibilities of care in advanced old age.

Higgs and Gilleard thus narrow their focus in this book from the general topic of the social and cultural construction of ageing to a theoretical argument about care at the end of life. They are not the first to identify the limitations and problems of care in these circumstances but stand out in taking a stance that exposes and challenges many of the commonly accepted platitudes that seek to cover up the dilemmas faced in the provision of such ongoing assistance.

Responding to the writings of Kitwood and Bredin (1992), they take particular aim at the concept of "personhood." Recognising the enduring personhood of people with advanced dementia is widely invoked as a sort of incantation for staff assigned to provide care to those with advanced dementia, it is not a satisfactory practical solution. Higgs and Gilleard argue that although the personhood approach calls on care staff to morally recognise the enduring personhood of such chronic care recipients, the recipients are no longer able to respond as full persons, because fourth age are recipients, by definition, lack the capacity to exercise agency or express full personhood. In such circumstances, the recipients are inherently vulnerable and dependent and providing care becomes increasingly one-sided.

Addressing the already considerable literature on both care and old age, Higgs and Gilleard present a quite in-depth review of much of the existing theory and some empirical research on each of the key terms in their theory. This approach provides the book's structure. Following an introductory chapter that provides an overview of the main argument, two chapters chart and review the literature regarding the meaning of the terms "personhood", "agency" and "identity", finding a significant difference in emphasis and meaning in the terms as used by philosophers, sociologists, other social scientists and popular culture. Using a similar theoretical and critical approach to the literature, the next two chapters analyse the concepts of frailty and abjection in some detail. 
A further two chapters then examine the theory and research on care - contrasting care based on informal caregiving for and between intimate family members with formal care, based on paid work, where the caring is concerned with the support of strangers. The result is a bleak portrayal of support in the final years that valorises informal care provided in families but points to its limits and the impact on family carers. It provides an even less optimistic analysis of the options for formal care. In the penultimate chapter, that seems to have been written with a view to providing some sense of hope, the authors write of "care without limits." It focuses on the support of those with advanced dementia as a proxy for those advanced age, identifying a stage in which people need care but are unable to actively exercise their rights and instead must depend on those responsible for their care.

Although some research results are reported from the literature, the book is most definitely not an empirical research study with a Cochrane-like statement of established evidence. Rather, its intent and value is as theory, the conclusions providing a rich set of well-founded propositions, interpretations and argument with which to both guide further research on the one hand and stimulate reflection and invite further conceptual analysis on the other hand. The cultural analysis approach, which remains central to the theory construction, draws together key concepts such as "abjection" and "personhood" that are essentially symbolic and interpretative concepts with elements such as the experience of receiving care that may draw on observational as well as other qualitative, possibly subjective forms of data collection.

While some level of dispute is likely to arise over the practical questions of implementation and care practices - the impact of particular care settings, the approach of different teams and the practice of care under a range of different national or policy circumstances - others remain conceptual. I found myself constantly questioning the framing of the issue around the relevance of concepts such as the fourth age and abjection. Don't the arguments advanced about advanced age apply equally to the experience of conditions of severe and profound disability? If so, is this meditation on care really about the fourth age or about care where high levels of dependency are evident? Palliative care for dementia is touched upon briefly, but the broader topic of euthanasia or palliative care at the 
International Journal of Ageing and Later Life

end of life is not explored in any depth. Yet, these topics seem to fit the model centrally in terms of life stage and descriptions of dependency advanced by Higgs and Gilleard. The concept of abjection is also difficult as it seems to be used tautologically, as both the cause and the outcome of the very problems, such as sequestration and dependency, it seeks to explain. Is abjection essentially a term of description, or is it a cause or explanation? Indeed, might the entire argument be used simply as a sort of sophisticated justification for abandoning hope?

Perhaps the message emerging from the shadows of the book's analysis might be a need to confront the final stage of life by taking control at an early point, perhaps through euthanasia or technology. If the fourth age is best understood as a social imaginary rather than as a fact of life, might it be possible to replace the popular belief in decline and the need for care in the final years of life with a more realistic appraisal? If so, under what conditions?

The argument advanced in this book raises questions and doubts for other readers as it did for me; it will have more than served a valuable service. While it is unsettling, raising questions rather than providing answers, this is clearly the most stimulating theoretical account of the possibilities and limits of care in advanced old age that I have read. I strongly recommend it and hope that other researchers and practitioners will read this book and join the debate.

\section{References}

Gilleard, C. \& Higgs, P. (2000). Cultures of Ageing: Self, Citizen and the Body. London: Prentice Hall.

Gilleard, C. \& Higgs, P. (2010). Aging without agency: Theorizing the fourth age. Aging \& Mental Health 14(2): 121-128.

Higgs, P. \& Gilleard, C. (2014). Frailty, abjection and the "othering" of the fourth age. Health Sociology Review 23(1): 10-19.

Higgs, P. \& Gilleard, C. (2015). Rethinking Old Age: Theorising the Fourth Age. London: Palgrave MacMillan.

Kitwood, T. M. \& Bredin, K. (1992). Towards a theory of dementia care: Personhood and wellbeing. Ageing \& Society 12(3): 269-287. 